the organ donors in this study were asymptomatic for KS disease, the results imply that KS tumor cells or their progenitors form continually in infected individuals but are suppressed or killed through normal immune surveillance.

It appears, then, that preformed tumor cell precursors escape normal proliferative controls when introduced into an immunocompromised milieu. This notion could explain why stopping immunosuppressive therapy works as a treatment for transplant-related KS. Perhaps stopping therapy permits host recognition of foreign donor-derived cellular antigens as well as virus antigens.

The new data revisit an idea that has been around for some time. Robin Weiss and Harold Jaffe attempted to demonstrate cellular transmission of $\mathrm{KS}$ in humans based on knowledge about transmissible canine venereal tumor. This canine sarcoma is sexually transmitted from cells shed during intercourse and forms an in- dolent, localized tumor under tight immunologic control ${ }^{7}$.

Despite their frightening degree of biologic insight, Weiss and Jaffe were unsuccessful because of the techniques available to them at the time. It no longer seems preposterous to propose that a fraction of sexually transmitted KS tumors might also be caused by cellular transmission, particularly among AIDS patients.

The biology of KSHV holds a wealth of clues on how to attack this virus in the clinic. Unfortunately, KS highlights the gap between research and patient management more acutely than almost any other condition. Despite the advances made in understanding the basic biology of KSHV, there has been little change in actual clinical practices since the virus was discovered in 1994. KS is now the single most frequently reported neoplasm in many subSaharan countries.

Lack of clinical progress is not due to a lack of new tools. These include diagnos- tic tests, novel drug therapies and behavioral studies to prevent transmission; it is simply that these tools are not being used. Nor is there significant movement on this front. At the simplest level, monitoring for KSHV infection among transplant donors and recipients seems eminently reasonable and can be implemented immediately. The relatively low rate of KSHV positivity means that few organs will be rejected as unsuitable for transplantation. A recent multicenter analysis suggests that approximately 3\% of US blood donors are KSHV-positive (P. Pellett, personal communication); these results are within the estimated limits from the earliest studies published in this journal seven years ago ${ }^{8,9}$.

The consequences of KSHV infection after transplantation-whether latent in the patient or received from the donorare serious. Over $50 \%$ of KSHV-positive, immunosuppressed recipients develop tumors under some circumstances ${ }^{10}$. The real

\title{
Mysticism to medicine
}

In the third century after Christ, the Saints Cosma and Damiano, a medical doctor and chemist, respectively, replaced the gangrenous leg of the Roman deacon Justinian with a leg from a recently buried Ethiopian Moor. Jacopo da Varagine described this legend in his Leggenda Aura in the thirteenth century, and the Italian painter Beato Angelico represented it in his 1438-40 masterpiece, The miracle of transplantation (shown here). These saints, who treated patients for a variety of ailments without charge, had performed the first cadaveric allograft.

For centuries thereafter, attempts at transplantation consisted of crude, rare and desperate measures-usually unsuccessful. That began to change in 1902, when the French surgeon Alexis Carrel developed the revolutionary technique of vascular anastomosis, where one blood vessel is attached to another. This advance allowed the first heart and kidney transplantations in animals ${ }^{1}$. In the 1940s, Sir Peter Brian Medawar, while attempting the first skin

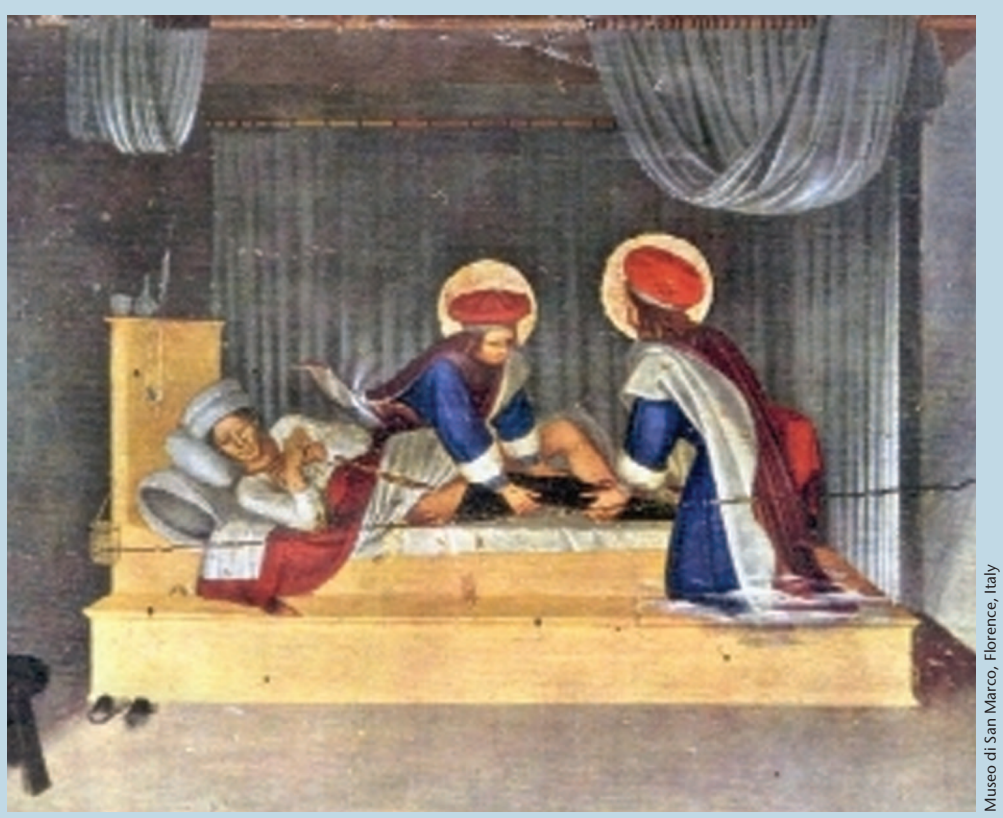
grafts to cure wounded soldiers in the Second World War, recognized the significance of donor leukocytes in inducing transplant immunity and accelerated rejection of skin grafts. Finally, in 1954, the surgeon Joseph E. Murray performed the first renal homotransplantation in identical twins ${ }^{2}$.

The discovery of cyclosporin, the first selective immunosuppressant agent, by Jean F. Borel in the 1970s, ultimately moved transplantation from the realm of curiosity into routine therapy ${ }^{3}$. Today, over 40,000 organs are transplanted each year in the US and Europe; some of them are tainted with KSHV or Kaposi sarcoma tumor progenitors ${ }^{4}$. The first case of post-transplant Kaposi sarcoma was observed in 1969 in a woman who had received a kidney from a cadaveric donor ${ }^{5}$.

1. Carrel, A. \& Guthrie, C.C. Anastomosis of blood vessels by the patching method and transplantation of the kidney. 1906 classical article. Yale J. Biol. Med. 74 243-247 (2001).

Murray, J.E., Merrilland, J.P. \& Harrison, J.H. Renal homotransplantation in identical twins. J. Am. Soc. Nephrol. 12, 201-204 (2001)

Borel, J.F. et al. Biological effects of cyclosporin A: a new antilymphocytic agent. Agents Action 6, 468-475 (1976).

Barozzi, P. et al. Post-transplant Kaposi sarcoma originates from the seeding of donor-derived progenitors. Nat. Med. 9, 554-561 (2003)/

Siegel, J.H. et al. Disseminated visceral Kaposi's sarcoma. JAMA 207, 1493-1496 (1969).

PATRIZIA BAROZZI, MARIO LuPPI \& GiUSEPPE TORELli 